\title{
On the effectiveness of treatment options in epistaxis: an analysis of 678 interventions*
}

\author{
Michael B. Soyka ${ }^{1,2}$, Georgios Nikolaou ${ }^{1}$, Kaspar Rufibach ${ }^{3}$, David Holzmann ${ }^{1}$ \\ Department of Otorhinolaryngology, Head and Neck Surgery, University Hospital of Zurich, Switzerland \\ Swiss Institute of Allergy and Asthma Research (SIAF), Davos, Switzerland \\ 3 Division of Biostatistics, Institute for Social and Preventive Medicine, University of Zurich, Switzerland
}

\begin{abstract}
SUMMARY Background: Epistaxis represents one of the most common emergencies in ENT clinics around the world. It creates great physical and emotional stress to the patient as well as a financial burden on health-care systems. A lot of research has been performed with regard to aetiology and possible treatment, however, not much effort has been put into analysing the effectiveness of common treatment forms. It is the objective of this study to clarify which of these treatment forms is reliable.

Study design: Retrospective cohort study. Level of Evidence: $2 b$.

Methods: Between 03/2007 and 04/2008, all epistaxis therapies including relapses and treatment failures at the University Hospital of Zurich have been documented using a computerised questionnaire. Different treatments were compared to each other.

Results: An analysis of 678 interventions in 537 patients was performed with emphasis on failure proportions and time to occurrence. The estimated failure proportions of coagulation in anterior epistaxis accounts for 14\%. Successful treatment of epistaxis in posterior bleedings could be achieved in $62 \%$ by packing and in $97 \%$ by surgery with a statistically significant difference between the respective groups.

Conclusion: Using our treatment options, anterior epistaxis can be cured reliably by cauterisation. Surgical therapies in posterior bleedings are able to successfully salvage failed packing therapies.
\end{abstract}

Key words: epistaxis, therapy, treatment efficacy, electrocoagulation, surgery

\section{INTRODUCTION}

Epistaxis is a common disorder in the human population. Although not always requiring medical attention, it still represents the most common emergency in ENT clinics around the world ${ }^{(1)}$. The event of a nosebleed is typically very stressful for the patient even before initiating treatment. A variety of treatment options exist but still it is quite challenging to choose a reliable and safe one. In our department, we follow a treatment plan that has previously been published (2). However, doctors are still free in choosing between the different and interchangeable treatment types. For anteriorly located bleeders, we may use electric or chemical cautery; a pack is very rarely needed. For posterior epistaxis, a thorough nasal endoscopy is performed whenever possible to localise and cauterise a bleeding source. As this is rarely the case, we usually place an inflatable Rapid Rhino ${ }^{\circledR}$ packing $(7.5 \mathrm{~cm}$ anterior-posterior,
ENT Arthrocare Europe, Stockholm, Sweden). In case of a treatment failure, we then step on forward and insert a Foley balloon catheter and pack the nose with fat-gauze. As a final option, we perform rigid nasal endoscopy in general anaesthesia and electrocoagulate any visible bleeding vessels. In all cases, endonasal sphenopalatine artery ligation of all its branches is undertaken. If the bleeding persists or the source is clearly located in the supply area of the ethmoidal arteries, external closure is additionally performed by lynch incision. The objective of this study was to evaluate these approaches. The aim was to find out whether chemical cautery was superior to electrocoagulation in anterior bleedings. We also wanted to elucidate the success rates of packing and surgery as possible treatment choices for posteriorly located sources. The endpoints of this study were effectiveness of treatment and time to recurrence. 


\section{MATERIALS AND METHODS}

\section{Study}

The study was conducted in accordance with the latest version of the Helsinki declarations. The local ethics committee and review board approved the protocol.

\section{Patients}

We reviewed data of epistaxis patients that was collected prospectively in an electronic database at the ENT department of the University Hospital of Zurich between 03/2007 and 04/2008 in a study concerning the effects of acetylsalycilic acid ${ }^{(2)}$. The following information was recorded for each patient: age, sex, side of bleeding, visibility of bleeding source (i.e. anterior/posterior epistaxis), number of recurrences, dates of recurrences and types of treatments.

All patients were consecutively included. Bleedings secondary to trauma or caused by hemorrhagic teleangiectasia (M. Osler) were excluded. Coagulopathies, the use of antiaggregational agents such as acetylsalicylic acid or anticoagulants have been noted but did not lead to exclusion. The analysis of these risk factors on nose bleeding and its therapies have been previously published by our group ${ }^{(2)}$.

Patients with a nosebleed were treated according to the assessment and preferences of the treating resident, following the previously mentioned therapeutic algorithm. Therefore in cases of surgical treatment all patients had undergone previous packing of the nose.

Persistent bleeding despite treatment within 24 hours was counted as an immediate failure. Re-bleeding within 4 weeks on the same side was considered a recurrence. Bleedings thereafter were counted as new events.

\section{Statistics}

Nominal variables between groups were compared using Fisher's exact test. In this exploratory analysis, no correction for multiple testing was done and all tests with a p-value not larger than 0.05 were considered to be significant. For each failure proportion we additionally provide $95 \%$ confidence intervals according to Wilson's method. For time-to-event data we provide Kaplan-Meier estimates and $90 \%$ quantiles of the estimated survival curve, including $95 \%$ confidence intervals.

The statistical analysis was performed using SPSS software version 18 (SPSS Inc. Chicago, IL, USA). Wilson confidence intervals were calculated in $\mathrm{R}^{(3)}$.

\section{RESULTS}

From our database, 678 interventions could be retrieved that were undertaken in 537 patients. Nineteen cases had nonstandardised treatment (i.e. the treatment algorithm was not followed for any given reason), and therefore were excluded from statistical analysis to avoid a 'treatment bias.' The male to female ratio was 5:4 and median age was 70 (range 11 - 96) years. The results of the treatments can be viewed in Table 1. Most of the bleedings were localised anteriorly (71\%) and could be treated by bipolar coagulation or chemical cautery. Only $13(3 \%)$ obtained packing as the first treatment in anterior bleeding sources, the reasons were: bilateral or multiple bleeding sources, previous unsuccessful coagulation elsewhere and not being able to reach bleeding-source safely although visible. The success-proportion of the electric and chemical coagulation was 88 and $78 \%$ (failure proportion: $12 \%$ with $95 \%$ - CI $[0.09,0.16] ; 22 \%$ with $95 \%$-CI $[0.14,0.33])$, respectively. For posteriorly located sources (27\%) most of the patients were treated by inflatable carboxymethylcellulose Rapid Rhino ${ }^{\circledR}$ packing. The use of Foley catheters together with fat-gauze was less frequent. The failure proportions in these were 36 and $48 \%(95 \%$ - CI [0.28, 0.45]; 95\%-CI [0.30, 0.67]) respectively. In 9 patients $(2 \%)$, no data about localisation was available.

Best results could be achieved by surgical intervention. Only one of these (1/36; 3\%) failed 95\%- CI [0.00, 0.14]) and required embolisation, due to a contralaterally feeding anterior ethmoidal artery.

A significant difference between the failure proportions of coagulative treatments $(p=0.04)$ was detected using Fisher's exact test, in favour of the electrocautery. However, there was no difference between the two different packs that have been used $(p=0.27$ ). When comparing surgical results, surgery yielded significantly better outcome than packing alone ( $\mathrm{p}<$ 0.05 for both types, Foley catheter and Rapid Rhino ${ }^{\circledR}$ ).

We have had immediate, early and late failures of each treatment: the $90 \%$ recurrence free rates in Kaplan Meier analysis were 12 days $(95 \%$ - CI $[2, \infty])$ for electrocoagulation, 3 days (95\%- CI [0,8]) for chemocautery, 0 days $(95 \%$ - CI $[0,0])$ for Rapid Rhino ${ }^{\circledR}$ packing and 0 days $(95 \%$ - CI $[0,0])$ for Foley catheter packs (Figure 1). The only recurrence of surgical treatment occurred on day 14. Immediate failures were found in $20 / 49$ cases $(41 \%)(95 \%$ - CI $[0.28,0.55])$ for electrocoagulation, $5 / 16$ cases $(31 \%)(95 \%$ - CI $[0.14,0.56])$ for chemocautery, $34 / 47(72 \%)(95 \%$ - CI $[0.58,0.83])$ cases for Rapid Rhino ${ }^{\circledR}$ packing, $8 / 12$ cases $(67 \%)(95 \%$ - CI $[0.39,0.86])$ for Foley catheter packs.

\section{DISCUSSION}

Using the results of this study, we are able to discuss the efficacy of our treatment algorithm. It focuses on the main interest of each patient: successful therapy. The limitations of our work are the retrospective nature, where (although prospectively collected) data might have been recorded falsely and recurrences treated outside our institution might have got lost. In addition, patients' preferences regarding treatment (i.e. after previous painful packing procedure) might have biased the treatment pathway as well.

As the treatment choice was at the doctors' discretion, we clearly have a selection bias, especially in anterior bleeders. In an arterial, pulsating, heavy bleeding most residents would prefer treating with electrocautery rather than chemocoagulation. Furthermore, no follow-up visits were done to assess quality of life after treatment. 
Table 1. Success rates of treatments with $95 \%$ Wilson confidence intervals.

\begin{tabular}{|c|c|c|c|c|}
\hline Treatment & $\begin{array}{l}\text { Total No } \\
(n=659)\end{array}$ & $\begin{array}{c}\text { Failures as firstline } \\
\text { treatment } \\
{[95 \% \mathrm{CI}]}\end{array}$ & $\begin{array}{c}\text { Failures as secondline } \\
\text { treatment } \\
{[95 \% \mathrm{CI}]}\end{array}$ & $\begin{array}{c}\text { Total } \\
\text { Failures } \\
{[95 \% \text { CI] }}\end{array}$ \\
\hline Chemical coagulation & 73 & $\begin{array}{c}16(22 \%) \\
{[0.14,0.33]}\end{array}$ & $\begin{array}{c}0(0 \%) \\
{[0.00,0.05]}\end{array}$ & $\begin{array}{c}16(22 \%) \\
{[0.14,0.33]}\end{array}$ \\
\hline Bipolar coagulation & 397 & $\begin{array}{c}47(12 \%) \\
{[0.09,0.15]}\end{array}$ & $\begin{array}{c}2(0.5 \%) \\
{[0.00,0.02]}\end{array}$ & $\begin{array}{c}49(12 \%) \\
{[0.09,0.16]}\end{array}$ \\
\hline Rapid Rhino ${ }^{\circledast}$ Packing & 128 & $\begin{array}{c}35(27 \%) \\
{[0.20,0.36]}\end{array}$ & $\begin{array}{c}11(9 \%) \\
{[0.05,015]}\end{array}$ & $\begin{array}{c}46(36 \%) \\
{[0.28,0.45]}\end{array}$ \\
\hline Balloon Packing & 25 & $\begin{array}{c}6(24 \%) \\
{[0.12,0.43]}\end{array}$ & $\begin{array}{c}6(24 \%) \\
{[0.12,0.43]}\end{array}$ & $\begin{array}{c}12(48 \%) \\
{[0.30,0.67]}\end{array}$ \\
\hline Surgery endonasal & 31 & $\begin{array}{c}0(0 \%) \\
{[0.00,0.11]}\end{array}$ & $\begin{array}{c}0(0 \%) \\
{[0.00,0.11]}\end{array}$ & $\begin{array}{c}0(0 \%) \\
{[0.00,0.11]}\end{array}$ \\
\hline Surgery endonasal and external & 5 & $\begin{array}{c}0(0 \%) \\
{[0.00,0.43]}\end{array}$ & $\begin{array}{c}1(20 \%) \\
{[0.04,0.62]}\end{array}$ & $\begin{array}{c}1(20 \%) \\
{[0.04,0.62]}\end{array}$ \\
\hline
\end{tabular}

\section{Efficacy}

Efficacy in terms of bleeding control can be drawn directly from our results. When comparing the results of electrocoagulation and chemocautery, there was a small but significant difference (better results in electrocoagulation) with a clinically relevant divergence of $10 \%$. Accounting for the above-mentioned bias, it is obvious that electrocoagulation has only little less failures than any other non-surgical treatment form in anterior epistaxis; this is in accordance with other studies ${ }^{(4)}$. In our study, surgery was very effective. It was able to successfully treat posterior epistaxis, when packing has failed, irrespective of whether it was used in immediate failures of previous therapies or after several days. Although a direct comparison of surgery and packing is not possible, as all patients that were operated had some sort of packing previously, its high efficiency is striking. Accounting for the fact that it was able to provide a final treatment even in 'difficult' situations, surgery could also form a considerable choice as a first line cure instead of applying different and even painful packs. The overall effectiveness of surgery in epistaxis has also been proven by other authors ${ }^{(5-8)}$. The two types of packing showed recurrences in more than one third of all cases, which again is in concordance with previous reports ${ }^{(9)}$. We have to be aware that the use of Foley catheters as nasal packs are not approved and consist of an off label use. It is known that inadequate inflation of the catheter especially when filled with air may fail to seal the choana ${ }^{(10)}$. We have not investigated whether the balloon was filled adequately with water or air, and therefore may be a source of failure ${ }^{(11)}$.

\section{Safety and complications}

The complications of different treatments have been published previously. We still need to discuss every single therapeutic form in order to balance all advantages and disadvantages ${ }^{(2)}$.
Anterior coagulation, whether chemical or electric, is usually performed in surface-anaesthesia using soaked cotton pledges. This of course bears the risk of allergic reactions to the local anaesthetic and anaphylaxis, however it can be minimised by obtaining an adequate medical-history. The addition of epinephrine also creates a small risk of cardiac events (12). Coagulation, especially when applied on both sides of the septum, may lead to necrosis, synechia, scarring and perforation ${ }^{(13,14)}$. Packing, especially when used in posterior bleedings, bears different potentially lethal complications. Upon insertion a naso-vagal reflex can be triggered and lead to cardiac dysfunction ${ }^{(15)}$. If not secured properly packs can get swallowed or even worse aspirated into the lungs ${ }^{(16)}$. Securing of the pack on the other hand can lead to alar or columellar necrosis ${ }^{(17)}$. Colonisation of the tampon may be followed by infections and sometimes although rarely cause toxic shock syndrome ${ }^{(18)}$. Last but not least, nasal packs may lead to oxygen desaturation and hypercapnia by nasopulmonary reflex and iatrogenic obstructive sleep apnea and can hereby be lethal in cardio-pulmonary ill patients ${ }^{(13,19,20)}$. In traumatic cases a Foley catheter can even migrate through the skull base ${ }^{(21,22)}$. Endoscopic ligation of the SPA and external approaches to the ethmoidal arteries are performed in general anaesthesia at our institution ${ }^{(5)}$. This of course bears all the known risks of the anaesthetic procedure ${ }^{(23)}$. Complications of sphenopalatine artery closure comprises of the same events as in other endoscopic surgical procedures. We have described these earlier in detail ${ }^{(24)}$. Local wound healing impairment and necrosis may also occur ${ }^{(25)}$. We know from one of our previous studies that younger doctors will not have more complications in ESS procedures when trained adequately ${ }^{(24)}$.

Pain

There is scarce literature about the impact of an epistaxis- 


\section{Kaplan-Meier estimate for time to recurrence}

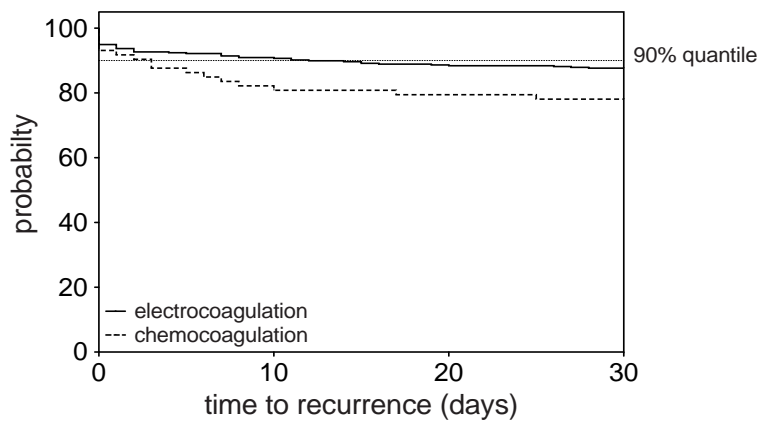

Kaplan-Meier estimate for time to recurrence

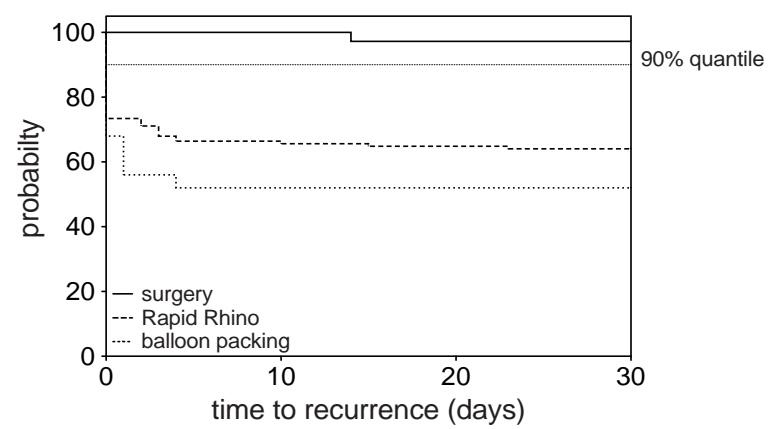

Figure 1. Kaplan-Meier estimates for time to event, provided separately for cautery and packing/surgery.

treatment on the patient in terms of discomfort and pain. As one can imagine chemocoagulation has been reported to be less alarming to a patient than electorcoagulation ${ }^{(4)}$. Rapid Rhino ${ }^{\circledR}$ treatment has often been compared to other packings and been shown to be less painful than these ${ }^{(26-29)}$. However, these studies have either been done for anterior epistaxis or were performed in general anaesthesia, and mostly compared non-coated sponges, that are prone to adhesion to the mucosa (30). To our knowledge, there is no comparison with balloon packing so far.

\section{Costs}

Some 20 years ago, Shaitkin et al. reported that surgical treatment was more costly than packing ${ }^{(31)}$. Other studies had similar results, without taking failures into account ${ }^{(32,33)}$. However, when used directly as a first line treatment, it might cause less financial burden ${ }^{(34)}$.

\section{Alternatives}

In our work, we did not assess different alternative therapeutic options. Hot water irrigation is not available at our institution but was concluded to be equally effective as packing, less traumatic and therefore less painful ${ }^{(35,36)}$. Embolisation is extremely effective but not readily available, so only failed surgical treatments will be cured by this procedure at our institution. It also bears different complications that may range from local ischemia to blindness and even hemiparesis ${ }^{(37)}$. Haemostatic sealants such as Floseal ${ }^{\circledR}$ are probably also effective, but were only tested in anterior epistaxis and are currently quite high in price ${ }^{(38)}$.

In general anaesthesia bleeding sources can often be localised and directly cauterised with good results even without the closure of the main trunk of a bleeding artery ${ }^{(39)}$. Performing thorough endoscopy with monopolar coagulation in the setting of better local, or rather regional, anaesthesia might be another option to be considered.

Foley catheters conjoined with the insertion of fat gauze is regarded as the 'ultima ratio' in packing for intractable epistaxis at our institution. We are fully aware of the presence of prefabricated catheters and double balloon packs. However,
Foley catheters are less costly and also allow us to pack even anatomically difficult nasal cavities, as the fat gauze can nicely be fitted according to the patient's needs.

Lastly, we prefer the use of Rapid Rhino ${ }^{\circledR}$ packs over (covered) Merocel $^{\circledR}$ tampons as they are equally effective but create less pain upon insertion and removal ${ }^{(27)}$. Furthermore, they are coated with a methylcellulose surface that facilitates coagulation. Whenever Merocel ${ }^{\circledR}$ tampons came into use during the study period, patients were excluded because of non-standardised treatment, as stated above.

\section{CONCLUSION}

This study shows the importance of the assessment of every treatment we perform in our daily practice. For the cure of anterior bleeding,s both treatment options we use were almost equally effective, with a slightly better result in electrocoagulation.

In posterior bleedings, we could show a high failure rate in nasal packing in terms of bleeding control. Surgery was clearly able to salvage these failed therapies.

Further studies are needed to analyse costs and patients' discomfort. They should be evaluated together with our findings to be able to give dedicated guidelines for the choice of therapeutic options in epistaxis.

\section{DISCLOSURES}

All authors state that there are no conflicts of interest to disclose. There are no financial disclosures.

\section{REFERENCES}

1. Small M, Murray J, Maran A. A study of patients with epistaxis requiring admission to hospital. Health Bull (Edinb). 1982; 40: 20-29.

2. Soyka M, Rufibach K, Huber A, Holzmann D. Is severe epistaxis associated with acetylsalicylic acid intake? Laryngoscope. 2010; 120: 200-207.

3. Team RDC. R: A language and environment for statistical computing. R: Foundation for Statistical Computing. 2008.

4. Toner J, Walby A. Comparison of electro and chemical cautery in the treatment of anterior epistaxis. J Laryngol Otol. 1990; 104: 617-618.

5. Holzmann D, Kaufmann T, Pedrini P, Valavanis A. Posterior 
epistaxis: endonasal exposure and occlusion of the branches of the sphenopalatine artery. Eur Arch Otorhinolaryngol. 2003; 260: 425-428.

6. Nouraei S, Maani T, Hajioff D, Saleh H, Mackay I. Outcome of endoscopic sphenopalatine artery occlusion for intractable epistaxis: a 10-year experience. Laryngoscope. 2007; 117: 1452-1456.

7. Feusi B, Holzmann D, Steurer J. Posterior epistaxis: systematic review on the effectiveness of surgical therapies. Rhinology. 2005; 43: 300-304

8. Minni A, Dragonetti A, Gera R, Barbaro M, Magliulo G, Filipo R. Endoscopic management of recurrent epistaxis: the experience of two metropolitan hospitals in Italy. Acta Otolaryngol. 2010.

9. Folz B, Kanne M, Werner J. Current aspects in epistaxis. HNO. 2008; 56: 1157-1165; quiz 66.

10. Lee $\mathrm{W}, \mathrm{Ku} \mathrm{P}$, van Hasselt C. Foley catheter action in the nasopharynx: a cadaveric study. Arch Otolaryngol Head Neck Surg. 2000; 126: 1130-1134.

11. Rashid M, Karagama Y. Inflation of Foley catheters for postnasal packing. J Laryngol Otol. 2010: 1-2.

12. Orlandi R, Warrier S, Sato S, Han J. Concentrated topical epinephrine is safe in endoscopic sinus surgery. Am J Rhinol Allergy. 2010; 24: 140-142.

13. Schreiner L. Complications and errors in the management of nose bleeding (author's transl). Laryngol Rhinol Otol (Stuttg) 1976; 55: 257-263.

14. Lloyd S, Almeyda J, Di Cuffa R, Shah K. The effect of silver nitrate on nasal septal cartilage. Ear Nose Throat J. 2005; 84: 41-44.

15. Fairbanks D. Complications of nasal packing. Otolaryngol Head Neck Surg. 1986; 94: 412-415.

16. Hashmi S, Gopaul S, Prinsley P, Sansom J. Swallowed nasal pack: a rare but serious complication of the management of epistaxis. J Laryngol Otol. 2004; 118: 372-373.

17. Civelek B, Kargi A, Sensöz O, Erdogan B. Rare complication of nasal packing: alar region necrosis. Otolaryngol Head Neck Surg 2000; 123: 656-657.

18. Nahass R, Gocke D. Toxic shock syndrome associated with use of a nasal tampon. Am J Med. 1988; 84: 629-631.

19. Beule A, Weber R, Kaftan H, Hosemann W. Review: pathophysiology and methodology of nasal packing. Laryngorhinootologie. 2004; 83: 534-51; quiz 53-56

20. Larsen K, Juul A. Arterial blood gases and pneumatic nasal packing in epistaxis. Laryngoscope. 1982; 92: 586-588.

21. Pawar S, Sharma R, Lad S. Intracranial migration of Foley catheter-an unusual complication. J Clin Neurosci. 2003; 10: 248-249.

22. Woo H, Bai C, Song S, Kim Y. Intracranial placement of a Foley catheter: a rare complication. Otolaryngol Head Neck Surg. 2008; 138: 115-116.

23. Gulur P, Nishimori M, Ballantyne J. Regional anaesthesia versus general anaesthesia, morbidity and mortality. Best Pract Res Clin Anaesthesiol. 2006; 20: 249-263.

24. Soyka M, Holzmann D. Correlation of complications during endoscopic sinus surgery with surgeon skill level and extent of surgery. Am J Rhinol. 2005; 19: 274-281.

25. Moorthy R, Anand R, Prior M, Scott P. Inferior turbinate necrosis following endoscopic sphenopalatine artery ligation. Otolaryngol Head Neck Surg. 2003; 129: 159-160.
26. Badran K, Malik T, Belloso A, Timms M. Randomized controlled trial comparing Merocel and RapidRhino packing in the management of anterior epistaxis. Clin Otolaryngol. 2005; 30: 333-337.

27. Moumoulidis I, Draper M, Patel H, Jani P, Price T. A prospective randomised controlled trial comparing Merocel and Rapid Rhino nasal tampons in the treatment of epistaxis. Eur Arch Otorhinolaryngol. 2006; 263: 719-722.

28. Chheda N, Katz A, Gynizio L, Singer A. The pain of nasal tampon removal after nasal surgery: a randomized control trial. Otolaryngol Head Neck Surg. 2009; 140: 215-217.

29. Singer A, Blanda M, Cronin K, et al. Comparison of nasal tampons for the treatment of epistaxis in the emergency department: a randomized controlled trial. Ann Emerg Med. 2005; 45: 134-139.

30. Garth R, Brightwell A. A comparison of packing materials used in nasal surgery. J Laryngol Otol. 1994; 108: 564-566.

31. Schaitkin B, Strauss M, Houck J. Epistaxis: medical versus surgical therapy: a comparison of efficacy, complications, and economic considerations. Laryngoscope. 1987; 97: 1392-1396.

32. Goddard J, Reiter E. Inpatient management of epistaxis: outcomes and cost. Otolaryngol Head Neck Surg. 2005; 132: 707-712.

33. Monte E, Belmont M, Wax M. Management paradigms for posterior epistaxis: A comparison of costs and complications. Otolaryngol Head Neck Surg. 1999; 121: 103-106.

34. Klotz D, Winkle M, Richmon J, Hengerer A. Surgical management of posterior epistaxis: a changing paradigm. Laryngoscope. 2002; 112: 1577-1582.

35. Stangerup S, Dommerby H, Siim C, Kemp L, Stage J. New modification of hot-water irrigation in the treatment of posterior epistaxis. Arch Otolaryngol Head Neck Surg. 1999; 125: 686-690.

36. Schlegel-Wagner C, Siekmann U, Linder T. Non-invasive treatment of intractable posterior epistaxis with hot-water irrigation. Rhinology. 2006; 44: 90-93.

37. Willems P, Farb R, Agid R. Endovascular treatment of epistaxis. AJNR Am J Neuroradiol. 2009; 30: 1637-1645.

38. Mathiasen R, Cruz R. Prospective, randomized, controlled clinical trial of a novel matrix hemostatic sealant in patients with acute anterior epistaxis. Laryngoscope 2005; 115: 899-902.

39. Thornton M, Mahesh B, Lang J. Posterior epistaxis: identification of common bleeding sites. Laryngoscope. 2005; 115: 588-590.

Michael Soyka, MD
Dept. Otolaryngology Head and Neck Surgery
University Hospital
CH 8091 Zurich
Switzerland

Tel: +41-44-255 1111

Fax: +41-44-255 4556

E-mail:michael@soyka.ch 